Article

\title{
Laser-Induced Interdigital Structured Graphene Electrodes Based Flexible Micro-Supercapacitor for Efficient Peak Energy Storage
}

\author{
Apurba Ray ${ }^{(D)}$, Jenny Roth and Bilge Saruhan * $\mathbb{D}$
}

check for updates

Citation: Ray, A.; Roth, J.; Saruhan, B. Laser-Induced Interdigital Structured Graphene Electrodes Based Flexible Micro-Supercapacitor for Efficient Peak Energy Storage. Molecules 2022, 27, 329. https://doi.org/10.3390/ molecules 27010329

Academic Editor: Chongjun Zhao

Received: 24 November 2021

Accepted: 1 January 2022

Published: 5 January 2022

Publisher's Note: MDPI stays neutral with regard to jurisdictional claims in published maps and institutional affiliations.

Copyright: (C) 2022 by the authors. Licensee MDPI, Basel, Switzerland. This article is an open access article distributed under the terms and conditions of the Creative Commons Attribution (CC BY) license (https:// creativecommons.org/licenses/by/ $4.0 /)$.
German Aerospace Center (DLR), Department of High-Temperature and Functional Coatings, Institute of Materials Research, 51147 Cologne, Germany; apurba.ray@dlr.de (A.R.); Jenny.vonWnuckLipinski@dlr.de (J.R.)

* Correspondence: bilge.saruhan@dlr.de

\begin{abstract}
The rapidly developing demand for lightweight portable electronics has accelerated advanced research on self-powered microsystems (SPMs) for peak power energy storage (ESs). In recent years, there has been, in this regard, a huge research interest in micro-supercapacitors for microelectronics application over micro-batteries due to their advantages of fast charge-discharge rate, high power density and long cycle-life. In this work, the optimization and fabrication of micro-supercapacitors (MSCs) by means of laser-induced interdigital structured graphene electrodes (LIG) has been reported. The flexible and scalable MSCs are fabricated by $\mathrm{CO}_{2}$-laser structuring of polyimide-based Kapton ${ }^{\circledR} \mathrm{HN}$ foils at ambient temperature yielding interdigital LIG-electrodes and using polymer gel electrolyte (PGE) produced by polypropylene carbonate (PPC) embedded ionic liquid of 1-ethyl-3-methyl-imidazolium-trifluoromethansulphonate [EMIM][OTf]. This MSC exhibits a wide stable potential window up to $2.0 \mathrm{~V}$, offering an areal capacitance of $1.75 \mathrm{mF} / \mathrm{cm}^{2}$ at a scan rate of $5.0 \mathrm{mV} / \mathrm{s}$ resulting in an energy density $\left(\mathrm{E}_{\mathrm{a}}\right)$ of $0.256 \mu \mathrm{Wh} / \mathrm{cm}^{2} @ 0.03 \mathrm{~mA} / \mathrm{cm}^{2}$ and power density $\left(\mathrm{P}_{\mathrm{a}}\right)$ of $0.11 \mathrm{~mW} / \mathrm{cm}^{2} @ 0.1 \mathrm{~mA} / \mathrm{cm}^{2}$. Overall electrochemical performance of this LIG/PGE-MSC is rounded with a good cyclic stability up to 10,000 cycles demonstrating its potential in terms of peak energy storage ability compared to the current thin film micro-supercapacitors.
\end{abstract}

Keywords: $\mathrm{CO}_{2}$-laser-induced graphene; ionic electrolyte; micro-supercapacitor

\section{Introduction}

Recently, the rapid growing development and demand of miniaturized portable and wearable electronics has expressively amplified the importance for lightweight, stretchable, microscale and efficient power storage systems [1-3]. Modern life is also becoming more expedient day by day by the extensively utilization of fast remote-control smart devices, gadgets and recent development of internet-of-things (IoT) systems [4,5]. An IoT system needs lot of devices and sensors to be useful in large scale industrial purposes. Sustainable energy harvesting technologies such as solar-cells, thermal or mechanical energy, wind power, piezoelectric or triboelectric nanogenerators, etc., are widely investigated as power resources for the sensors and devices of IoT [6,7]. However, the instability and intermittence of these power resources urgently require the development of high-performance energy storage systems (ESSs) well-matched with the present demand. Accordingly, different types of miniaturized electrochemical energy storage systems (ESS) such as micro-batteries (MBs), micro-supercapacitors (MSCs), etc., have been widely explored over recent years to develop efficient EES systems [8,9]. Up to date, market available MBs have exhibited promising performance as miniaturized EES systems, but it is still challenging to overcome their intrinsic limitations including low power density, low lifetime, etc., which hinder their practical application $[10,11]$. Alternatively, electrochemical capacitors or supercapacitors (SCs) have drawn lot of interest as a novel ESSs over MBs due to promising advantages 
such as high-power density, fast charge-discharge rates, long cycle life $(>10,000)$ and ease of integration with various electronic components. Recent research has found that the MSCs are particularly attractive as one of the most competitive high-power sources for future miniaturized IoT technologies due to high power density, small size, controllable patterning, large scale on-chip integration ability and long cycle life [4,12]. Usually, MSCs can be fabricated by different ways such as stacked thin films of the cell components or planar interdigitated methods, etc., and it has also been observed that the nanostructured functional materials such as polymer films, graphene, carbon-based nanocomposites electrodes based thin-film flat MSCs can be advanced components for modern integrated circuits. The charge storage mechanism via capacitive ion adsorption/desorption in porous carbon electrodes based MSC can offer high power density and long cycle life which can be characterized by rectangular shape of cyclic voltammograms $(\mathrm{CV})$ curves and linear nature of galvanostatic charge-discharge (GCD) curve at a constant current. Pseudocapacitive electrode materials based MSCs also exhibit similar features due to fast surface redox reactions of the cation in the active electrode material. There is no such phase change generally observed in redox active electrode materials during long cycle life which signifies the capacitive behavior of the MSC [7,13].

However, the up-to-date literature displays that the MSCs still have deficits in respect to simultaneous high specific capacitance and power density due to limited ionic conductivity of the applied solid electrolytes. One of the major issues that stand before the current practical application of MSC is its internal short circuit problem [14,15]. One promising way to overcome this challenge is to increase the electrode thickness by loading of more active electrode mass with a suitable interelectrode gap. Consequently, this method can enhance the charge transfer resistance but leads to lower power density. Thus, the simultaneous obtainment of high areal energy density as well as high power density at a MSC becomes a major challenge $[12,16]$. This issue can be encountered by coupling the nano-porous carbon electrodes with suitable electrolytes that offer a wide stable electrochemical potential window to accomplish superior MSCs exhibiting higher capacitance values, higher energy density and long cycle stability $[10,11,17]$.

Hence, this research work targets to emphasize the fabrication of LIG-based EDLC electrodes at ambient temperature for use in flexible and scalable micro-supercapacitor. Further ambition is to display the significant impact factors for achievement of improved MSC performance through embedded ionic liquid electrolyte and optimized ion transport pathways via the increased electrode porosity resulting in a wider potential window. In this context, we report the optimization and fabrication of MSCs based on laser-induced interdigital structured graphene electrodes fabricated by $\mathrm{CO}_{2}$-laser structuring of polyimide-based Kapton foils. Furthermore, PPC polymer matrix embedded [EMIM][OTf] ionic liquid is used yielding a polymer gel electrolyte (PGE). The detailed electrochemical device performance of this MSC have been carried out by cyclic voltammogram (CV), galvanostatic charge-discharge (GCD), electrochemical impedance spectroscopy (EIS) measurements and determination of cycle life by means of two-electrode measurements that are explained below.

\section{Results and Discussion}

The SEM images have been recorded at different magnifications of the samples at different condition to determine the change of surface morphologies of the PI-film before and after processing of irradiation with $\mathrm{CO}_{2}$-Laser. Figure S2 represents the influence of surface etching using $\mathrm{KOH}$-solution and it shows that the commercial PI-foil has a smooth surface except for a few minor visible scratches (Figure S1a). Nonuniform and agglomerated formation of $\mathrm{KOH}$ crystals (Figure S1b) is observed on the PI- surface due to the etching and drying process with $1 \mathrm{M} \mathrm{KOH}$ solution, but after etching and several times washing with DI- water for $\mathrm{KOH}$ removal, a clean and deeper indentation (Figure S1c) on the surface is observed. However, no noticeable reduction in PI film thickness is detected in the cross sections after the etching process. The top view SEM-image (Figure 1a) of the successful conversion of PI-foil surface into LIG exhibits a prominent porosity distribution 
on the surface of PI-foil after quite sharp and straight irradiation with Laser. The pore distribution on the electrode surface plays a vital role for electrochemical charge storage performance of a device $[18,19]$. Larger number of pores on the electrode surface enhances the infiltration of the electrolyte ions within the pores leading to the increase of capacitance value as well as energy density of the device $[17,20]$. The EDX mapping area (Figure 1b) with different colors also represents the oxygen rich (green color) and carbon rich (red color) areas of the LIG converted PI-foil. High intensity coloring represents a high atomic percentage of oxygen $(\mathrm{O})$ and carbon $(\mathrm{C})$ elements. As the investigated domains, PI and LIG are at different heights, a higher excitation voltage of $15 \mathrm{kV}$ was used. The SEM image (Figure 2a) shows the morphology of the LIG converted of from PI-foils with a laser power of $6 \mathrm{~W}$.

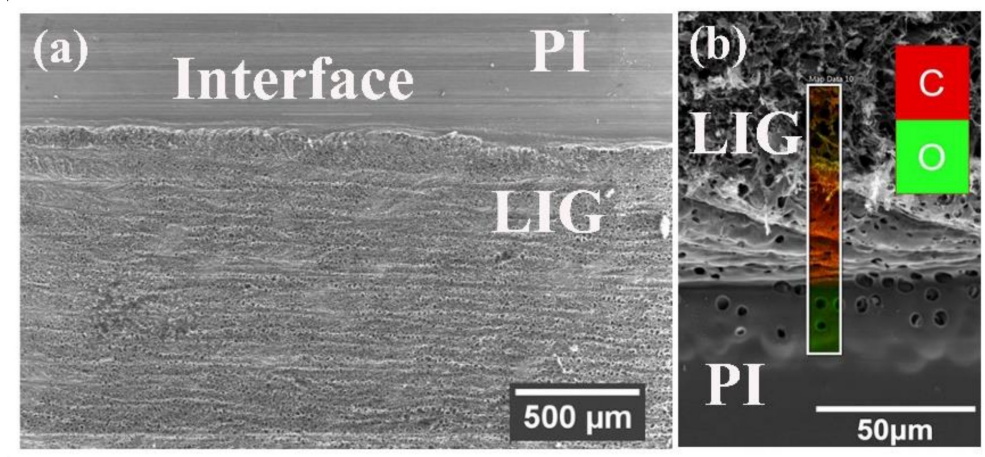

Figure 1. PI-foil converted to LIG (a) top view and (b) EDX mapping of the interface.
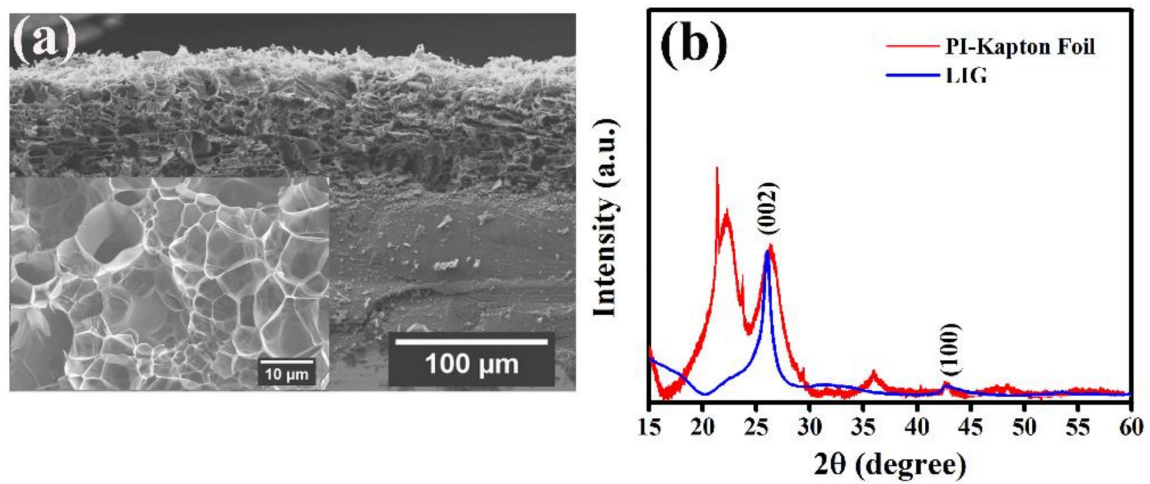

Figure 2. (a) Cross-section SEM images with porous structure view (inset) and (b) XRD plots of PI-Kapton foil and after conversion to LIG.

The conversion or yield of graphene layer thickness obtained through laser irradiation depends mainly on the laser power as well as surface treatment of the PI-foil. This is displayed by applying different laser powers and use of untreated and $\mathrm{KOH}$ surface treated foils. By starting with an untreated (no pre-treatment (No PT)) PI-foil of $125 \mu \mathrm{m}$ thickness and a laser power of $4.8 \mathrm{~W}$, approx. $18-30 \mu \mathrm{m}$ polymer was converted into porous carbonbased layer. The thickness of this resulting porous layer varied depending on the applied process parameters between $50-94 \mu \mathrm{m}$. The increase of laser power from $4.8 \mathrm{~W}$ to $5.6 \mathrm{~W}$ has also increased the converted PI-foil thickness from 18 to $31 \mu \mathrm{m}$. A further increase of the laser power to $6 \mathrm{~W}$, the penetration depth of the laser decreased to $20 \mu \mathrm{m}$, indicating a laser power of $5.6 \mathrm{~W}$ yields maximum conversion of the untreated PI-foil surface. On the other hand, a surface pre-treatment of the PI-foil using $\mathrm{KOH}(\mathrm{KOH}-\mathrm{PT})$ yields a significant growth of the LIG layer at higher laser powers (5.2-6 W). The maximum LIG layer thickness $(94 \mu \mathrm{m})$ has been achieved with $6 \mathrm{~W}$ and on the $\mathrm{KOH}$ pretreated PI-foils. These resulted also in better layer morphologies as well as higher yields. While the PI surfaces irradiated without any pretreatment deviated slightly from a linear increase. However, over $6 \mathrm{~W}$ 
exceeding increase of laser power (e.g., 6.4 and $8 \mathrm{~W}$ ) on $\mathrm{KOH}$-PT foil resulted in a largely deviating layer thickness and the wave-like surface topology.

Overall, it was observed that the surface porosity of the film is significantly different from the center of the film, i.e., when approaching towards the PI-surface, the pore diameters become more homogeneous and smaller. Approximately the porous LIG resulted through the conversion of Kapton foil has a thickness of varying between 50 and $94 \mu \mathrm{m}$. Conclusively, this micro-branched and/or columnar microstructure (Figure 2a, inset) of these porous LIG electrodes are beneficiary for electrolyte ions conduction providing short diffusion path.

The X-ray diffraction (XRD) spectroscopy measurement has also been performed to analyze the conversion of PI-foil to LIG. The XRD figures (Figure $2 b$ ) of bare PI-foil and LIG clearly demonstrate the successful conversion of PI-foil substrate to LIG-electrode. The broad polymer peaks at $2 \theta$ (degree) $=22.3,26.4$ and 36.0 of PI-foil have almost disappeared after laser treatment. The significant shift of the LIG samples towards a smaller angle $2 \theta($ degree $)=26.0$ and 42.7 results in larger interplanar spacing of about $3.6 \AA$, which may be due to the introduction of a several number of oxygen $(\mathrm{O})$-containing groups on each layer of LIG and conversion of LIG samples corresponding to the planes (002) and (100), respectively [21-24].

The electrochemical performance of as-prepared flexible LIGs / / LIGs symmetric microsupercapacitor (SMSC) has been firstly studied by cyclic voltammetry (CV) measurements (Figure 3a) at different scan rates from $5 \mathrm{mV} / \mathrm{s}$ to $100 \mathrm{mV} / \mathrm{s}$. The CV curves for this SMSC represents almost typical rectangular in shape within a wide stable electrochemical potential window from 0.0 to $2.0 \mathrm{~V}$, which reveals an ideal capacitive behavior of this LIG-electrodes [25]. The CV curves even at high scan rate of $100 \mathrm{mV} / \mathrm{s}$ continue to display the rectangular shape without any degradation, signifying a fast charge transfer capability within the electrode materials and relatively low equivalent series resistance (ESR) of this MSC. This flexible MSC also exhibits wide potential window up to $2.0 \mathrm{~V}$ with better rate performance compared to other interdigital structural MSCs [4,26-28]. The linear increase of capacitive current with increase of scan rates from $5 \mathrm{mV} / \mathrm{s}$ to $100 \mathrm{mV} / \mathrm{s}$ for this LIG-MSC is also observed, which suggests its fast electrolyte ions diffusion, fast charge transport and high-power output ability $[29,30]$. To the best of our knowledge, this LIG-MSC shows highest potential window up to $2.0 \mathrm{~V}$ with PPC polymer embedded [EMIM][OTf] ionic liquids-based electrolyte among all reported MSCs based on other graphene and carbon electrodes [31-34]. The capacitance value by means of total amount of charge stored in this LIG-MSC at a fixed scan rate can be determined from the total area covered by the $C V$ curve. The areal capacitance $\left(C_{A}\right)$ and specific capacitance $\left(C_{m}\right)$ are calculated from these CV curves using Equations (1) and (5), respectively. The maximum areal capacitance $\left(C_{A}\right)$ of $1.75 \mathrm{mF} / \mathrm{cm}^{2}$ and specific capacitance $\left(C_{m}\right)$ of $629.5 \mathrm{mF} / \mathrm{g}$, respectively is obtained at $5 \mathrm{mV} / \mathrm{s}$ scan rate. The variation of areal capacitance $\left(\mathrm{C}_{\mathrm{A}}\right)$ vs. scan rate (Figure $3 b$ ) represents that the capacitance value decreased with increasing scan rate due to limitation of ions movement from [EMIM][OTf]: PPC electrolyte to LIG-electrodes. At lower scan rates, the electrolyte ions $\left.[\mathrm{EMIM}]^{+} /{ }^{[\mathrm{OTf}}\right]^{-}$from electrolyte can take longer time to infiltrate within the electrode pores and thus, can access into the maximum inner and outer surface of the LIG-electrodes [35-37]. Therefore, the number of accumulated charges increase in the electrode/electrolyte interface, leading to the increase of capacitance value. Consequently, the mobility of charges per unit time increases at higher scan rates resulting in the charges access solely at the outer surface of the electrodes. Hence, the capacitance value decreases due to a smaller number of charge accumulation on the electrode/electrolyte interface [38-40]. On the other hand, these LIG-electrodes can also provide larger specific surface area and more electrochemical active surface sites for fully accessibility of electrolyte ions via adsorption/desorption to significantly enhance the charge capacitive performance of the MSC device. 

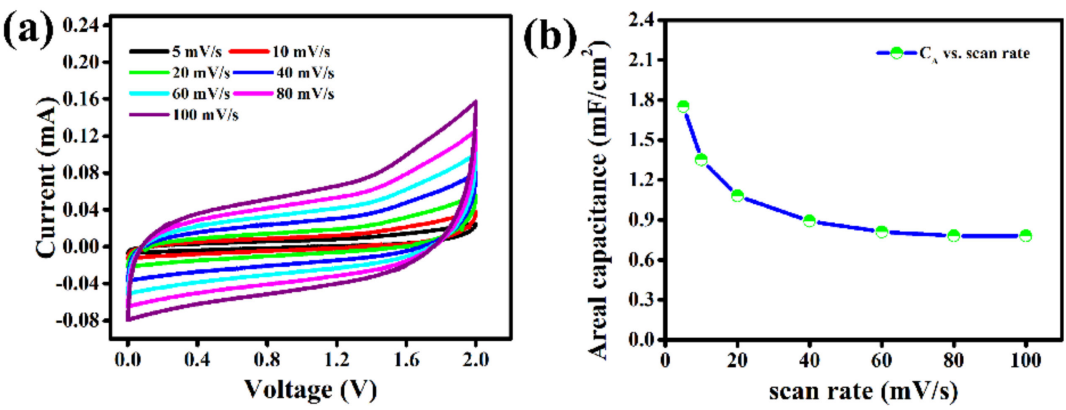

Figure 3. (a) Cyclic voltammograms at different scan rates and (b) areal capacitance vs. scan rate plot of LIG-MSC.

In order to investigate the charge/discharge behavior of this LIG-MSC, the galvanostatic charge/discharge (GCD) studies at different current densities $(0.03,0.05,0.07$ and $0.10 \mathrm{~mA} / \mathrm{cm}^{2}$ ) are performed. The GCD curves (Figure 4a) for all currents are symmetric in nature implying typical non-faradic or EDLC charge storage mechanism of these LIGelectrodes. Low voltage drops (IR-drop) at the starting of discharge curves even at higher currents signifies good reversibility, low electrolyte resistance as well as good electrical contact between electrodes and PI-current collector. However, the porous morphology of this LIG-electrode plays a significant role to accelerate the movement of [EMIM] ${ }^{+}$cations and [OTf $]^{-}$anions through electrode channels inside the pores indicating good capacitive behavior of this MSC. The areal capacitance $\left(C_{A}\right)$ and specific capacitance $\left(C_{m}\right)$ are also calculated from GCD curves at different current densities using Equations (2) and (6). The maximum areal capacitance $\left(\mathrm{C}_{\mathrm{A}}\right)$ of $0.461 \mathrm{mF} / \mathrm{cm}^{2}$ and specific capacitance $\left(\mathrm{C}_{\mathrm{m}}\right)$ of 166.1 $\mathrm{mF} / \mathrm{g}$ are obtained at $0.03 \mathrm{~mA} / \mathrm{cm}^{2}$ current density (Table S1). Areal capacitance $\left(\mathrm{C}_{\mathrm{A}}\right) \mathrm{vs}$. current density curve (Figure $4 \mathrm{~b}$ ) reveals that the capacitance value decreased with increase of current densities due to limited mobility and accessibility of the electrolyte ions at higher current densities as discussed earlier [12,41]. The Ragone plot drawn by means of areal energy density $\left(\mathrm{E}_{\mathrm{A}}\right)$ vs. areal power density $\left(\mathrm{P}_{\mathrm{A}}\right)$ of this LIG- electrode based MSC device (Figure 5a) exhibits that maximum areal energy density of $0.256 \mu \mathrm{Wh} / \mathrm{cm}^{2} @ 0.03 \mathrm{~mA} / \mathrm{cm}^{2}$ and areal power density of $0.11 \mathrm{~mW} / \mathrm{cm}^{2} @ 0.10 \mathrm{~mA} / \mathrm{cm}^{2}$, are achievable (Table S1). The overall electrochemical performance of this LIG-MSC comparison with other reported work has been presented in Table 1.
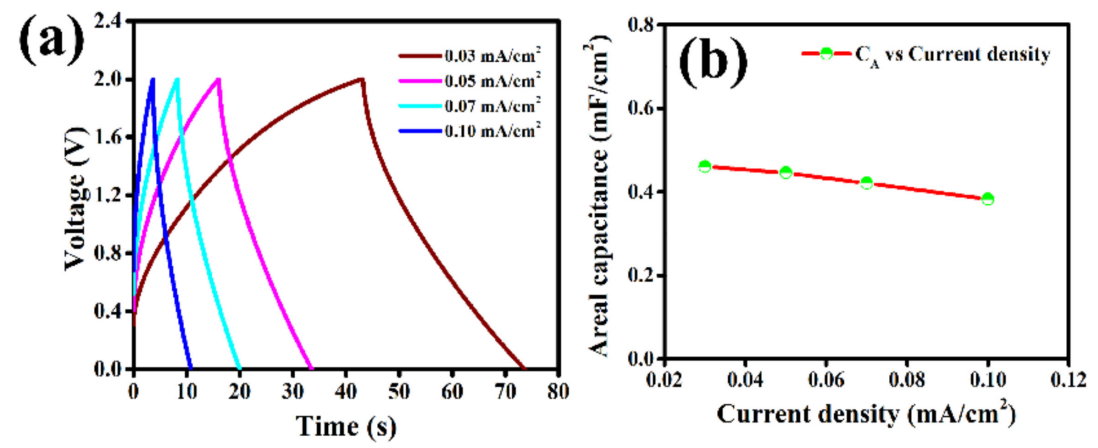

Figure 4. (a) Galvanostatic charge/discharge curves at different current density and (b) areal capacitance vs current density plot of LIG-MSC. 

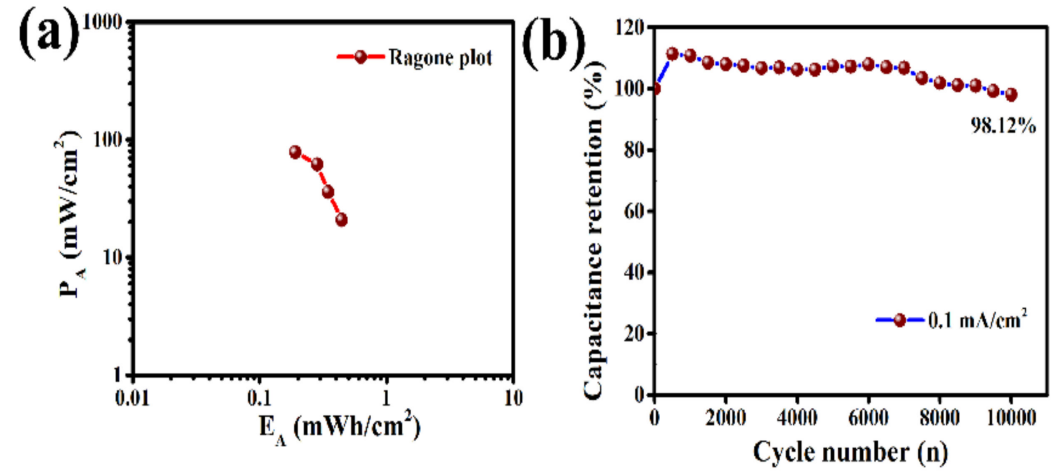

Figure 5. (a) Ragone plot and (b) capacitance retention vs. cycle number plot of LIG-MSC.

Table 1. Some typical MSC device performance selected from literature.

\begin{tabular}{|c|c|c|c|c|c|c|c|c|}
\hline Materials & $\begin{array}{l}\text { Synthesis } \\
\text { Method }\end{array}$ & $\begin{array}{l}\text { Type of } \\
\text { SC }\end{array}$ & Electrolyte & Capacitance & $\begin{array}{l}\text { Energy } \\
\text { Density }\end{array}$ & $\begin{array}{l}\text { Power } \\
\text { Density }\end{array}$ & $\begin{array}{l}\text { Potential } \\
\text { Window }\end{array}$ & Ref. \\
\hline $\begin{array}{l}\text { Ink-carbon } \\
\text { fiber }\end{array}$ & coated by ink & SSC & LiCl-PVA & $\begin{array}{c}4.3 \\
\mathrm{mF} / \mathrm{cm}^{2}\end{array}$ & $\begin{array}{l}34 \mu \mathrm{W} \\
\mathrm{h} / \mathrm{cm}^{2}\end{array}$ & $\begin{array}{c}0.38 \mu \mathrm{W} / \\
\mathrm{cm}^{2}\end{array}$ & $0.8 \mathrm{~V}$ & [42] \\
\hline rGO & $\begin{array}{l}\text { "in-plane" } \\
\text { fabrication } \\
\text { approach }\end{array}$ & ASC & PVA & $\begin{array}{c}<0.4 \\
\mathrm{mF} / \mathrm{cm}^{2}\end{array}$ & $\begin{array}{c}0.01 \mu W h \\
/ \mathrm{cm}^{2}\end{array}$ & $9 \mu \mathrm{W} / \mathrm{cm}^{2}$ & $1.0 \mathrm{~V}$ & [34] \\
\hline Graphene & electrodeposition & ASC & $\begin{array}{c}0.5 \mathrm{M} \mathrm{Na}_{2} \\
\mathrm{SO}_{4}\end{array}$ & $\begin{array}{c}0.5 \\
\mathrm{mF} / \mathrm{cm}^{2}\end{array}$ & $\begin{array}{c}0.07 \mu \mathrm{Wh} \\
/ \mathrm{cm}^{2}\end{array}$ & $\begin{array}{c}7.5 \mu W \\
/ \mathrm{cm}^{2}\end{array}$ & $0.9 \mathrm{~V}$ & [43] \\
\hline $\begin{array}{c}\text { Mushroom } \\
\text { derived } \\
\text { carbon (MDC) }\end{array}$ & $\begin{array}{c}\text { Scalable laser } \\
\text { scribing } \\
\text { technique }\end{array}$ & SSC & $\begin{array}{c}\text { PVA-H } \\
\mathrm{SO}_{4}\end{array}$ & $9 \mathrm{mF} / \mathrm{cm}^{2}$ & $\begin{array}{c}1.8 \mathrm{mWh} / \\
\mathrm{cm}^{3}\end{array}$ & $\begin{array}{c}720 \mathrm{~mW} / \\
\mathrm{cm}^{3}\end{array}$ & $1.0 \mathrm{~V}$ & [31] \\
\hline Carbon & $\begin{array}{l}\text { laser-induced } \\
\text { MOF-derived }\end{array}$ & SSC & $1 \mathrm{M} \mathrm{H}_{2} \mathrm{SO}_{4}$ & $\begin{array}{c}5.02 \\
\mathrm{mF} / \mathrm{cm}^{2}\end{array}$ & - & - & $1.0 \mathrm{~V}$ & [44] \\
\hline Graphene/CNTs & in situ & SSC & $\begin{array}{c}1 \mathrm{M} \mathrm{Na}_{2} \\
\mathrm{SO}_{4} \mathrm{IL}\end{array}$ & $\begin{array}{c}2.16 \\
\mathrm{mF} / \mathrm{cm}^{2}\end{array}$ & $\begin{array}{l}0.16 \mathrm{mWh} \\
/ \mathrm{cm}^{3}\end{array}$ & $\begin{array}{c}115 \mathrm{~W} / \\
\mathrm{cm}^{3}\end{array}$ & $1.0 \mathrm{~V}$ & [45] \\
\hline $\begin{array}{l}\text { Laser-Induced } \\
\text { Graphene } \\
\text { (LIG) }\end{array}$ & $\begin{array}{l}\text { Laser-induced } \\
\text { process }\end{array}$ & SSC & $\begin{array}{c}\text { [EMIM] } \\
\text { [OTf]:PPC } \\
\quad=0.5\end{array}$ & $\begin{array}{c}1.75 \\
\mathrm{mF} / \mathrm{cm}^{2}\end{array}$ & $\begin{array}{c}0.256 \\
\mu \mathrm{Wh} / \mathrm{cm}^{2}\end{array}$ & $\begin{array}{c}0.11 \\
\mathrm{~mW} / \mathrm{cm}^{2}\end{array}$ & $2.0 \mathrm{~V}$ & $\begin{array}{l}\text { This } \\
\text { work }\end{array}$ \\
\hline
\end{tabular}

The long cycle life study of this as prepared LIG-MSC device is also performed up to 10,000 cycles at a constant current of $0.1 \mathrm{~mA} / \mathrm{cm}^{2}$. The cycle performance of this MSC device (Figure $5 b$ ) shows good retention of $98.12 \%$ over 10,000 cycles. The initial capacitance value starts to increase with increasing cycle number up to 500 cycles, which may be due to the electrochemical activation effect of the LIG-electrode materials and then begins to decrease slightly and maintain almost same values $[25,46]$. It has been observed that the combination of these laser-induced interdigital structured graphene electrodes and PPC polymer embedded [EMIM][OTf] ionic electrolytes play a significant role for improvement of electrochemical performance and long cycle stability of this flexible MSC device. Overall, the good electrochemical performance and good cycle stability suggests that this laserinduced interdigital structured graphene electrodes based flexible micro-supercapacitor could be one of the promising energy storage systems for efficient peak energy storage in future.

The electrochemical impedance spectroscopy (EIS) study is performed over the applied frequency range from $100 \mathrm{kHz}$ to $0.01 \mathrm{~Hz}$ at AC perturbation amplitude of $10 \mathrm{mV}$ to understand the charge storage behavior of this device. The EIS plot (Figure 6) consists of two distinct portions, such as one depressed semicircle portion in high frequency region (Figure S3) corresponding to charge transfer resistance $\left(\mathrm{R}_{\mathrm{ct}}\right)$ and other inclined straightline portion in low frequency region corresponding to the charge diffusion resistance, called Warburg impedance $\left(\mathrm{W}_{0}\right)$, respectively. The initial intercept at the $\mathrm{Z}^{\prime}$-axis in the Nyquist plot represents the equivalent series resistance (ESR) or contact resistance $\left(R_{S}\right)$ 
due to the combination of electrolyte resistance and intrinsic resistance of LIG-electrode materials $[42,44]$. To get the equivalent circuit model, this EIS plot is well fitted using EC-Lab software as shown in Figure 6 (inset). Among three parts of the equivalent circuit, the first part provides the value of equivalent series resistance (ESR) or Rs of $752.1 \Omega$. The second part by means of parallel combination of constant phase element (CPE1), Warburg impedance $\left(W_{0}\right)$ and charge transfer resistance $\left(R_{c t}\right)$, respectively represents quite common charge transfer phenomenon of porous graphene electrodes. The relatively higher $\mathrm{R}_{\mathrm{ct}}$ of $348 \Omega$ signifies the lower infiltration of electrolyte ions or higher ionic transfer resistance effect within the smaller pores inside the electrode active sites $[9,11,17]$. The third portion of the circuit model CPE2 represents the electrochemical activity or kinetics occurred at the electrode/electrolyte interface of LIG-electrodes. The goodness of fitting factor $\chi^{2}$ ) of 0.00161 proposed good fitting of this EIS plot.

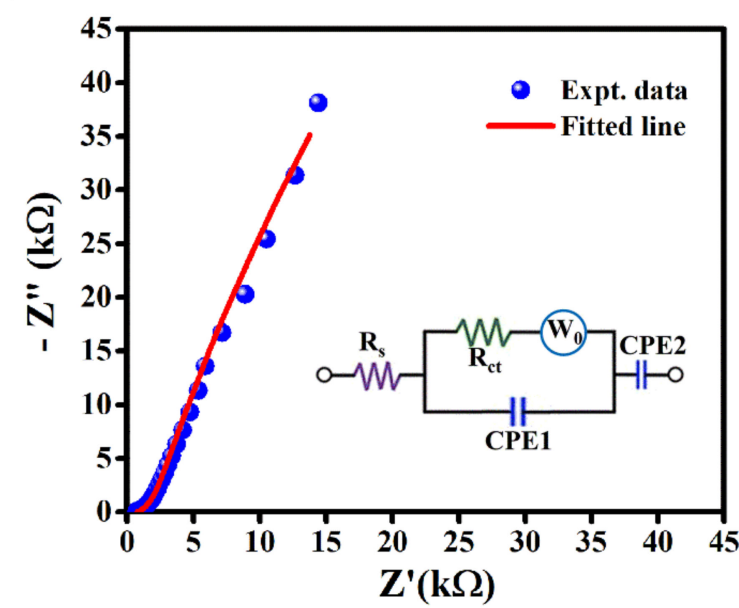

Figure 6. EIS plot and equivalent circuit model (inset) of this LIG-MSC.

\section{Materials and Methods}

\subsection{Materials}

The 1-ethyl-3-methyl-imidazolium-trifluoromethansulphonate [EMIM][OTf] (99\%, $\mathrm{M}=260.24 \mathrm{~g} \mathrm{~mol}^{-1}, \rho=1.39 \mathrm{~g} \mathrm{~cm}^{-3}$, IoLiTec, Heilbronn, Germany), polypropylene carbonate (PPC) (94.5\%, Mn=50,000 $\mathrm{g} \mathrm{mol}^{-1}$, Sigma Aldrich, Taufkirchen, Germany), acetonitrile (99\%, Sigma Aldrich), polyimide-based Kapton foils (Kapton ${ }^{\circledR}$ HN $125 \pm 13 \mu \mathrm{m}, \mathrm{CMC}$ Kleebetechnik, Germany), Isopropyl alcohol (IPA) (99.5\%, ACROS Organics) and potassium hydroxide $(\mathrm{KOH})(85 \%$, Riedel-de-Häen, Germany) were used for this experiment. All chemicals were of analytical grade and used without further purification.

\subsection{Fabrication of $\mathrm{CO}_{2}$-Laser-Induced Interdigital Structured Graphene Electrodes}

A commercial polyimide (PI)-based Kapton ${ }^{\circledR} \mathrm{HN}$ foil (hereafter given as Kapton Foil) with a thickness of $125 \mu \mathrm{m}$ was used as a flexible substrate and as the carbon precursor for the production of graphene layers. Prior to the laser irradiation with $\mathrm{CO}_{2}$-Laser, the Kapton foil surface was pretreated with a $1 \mathrm{M} \mathrm{KOH}$ solution. For that, the $\mathrm{KOH}$ solution was drop-casted onto the Kapton foil surface which was then dried in a vacuum desiccator for overnight under reduced pressure. Following this, the Kapton foil was attached onto an aluminum oxide ceramic plate by means of a double-sided Kapton tape to fix and stabilize the Kapton foil for further irradiation processing with $\mathrm{CO}_{2}$-Laser (supplied by VE-VOR, Germany). The irradiated Kapton foil was washed with isopropanol solution and dried in a vacuum desiccator over silica gel pellets at reduced pressure. After this pretreatment and stabilization, the Kapton foil was scanned in a continuous wave (CW) $\mathrm{CO}_{2}$-Laser engraving machine with $\lambda=10.6 \mu \mathrm{m}$ in the geometry shown in Figure 7 . The dimension of such fabricated MSC-devices was $24 \times 10.5 \mathrm{~mm}$. The interdigital Graphene electrodes displayed a hair comb formation which had 12 branches of $7.5 \times 0.8 \mathrm{~mm}$ equally distributed on 
each bar of the comb (Figure S2). The laser scanning speed was $8 \mathrm{~mm} \mathrm{~s}^{-1}$ and had a laser power of $15 \%$ of the maximum power being equivalent to $6.0 \mathrm{~W}$. The distance between the lens and substrate was $55 \mathrm{~mm}$. The manufacturing of the cells was performed at room temperature and in ambient air.
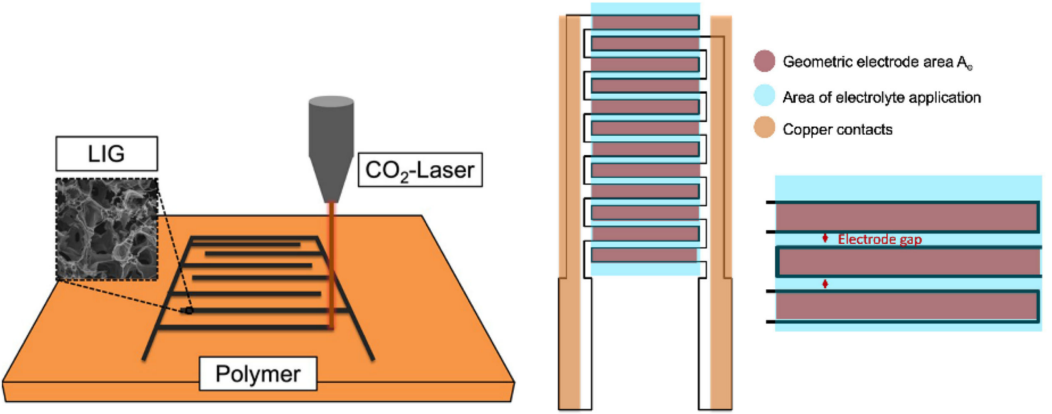

Figure 7. Schematic sketch of the converting PI-foil into porous LIG and sketch of an In-plane micro-supercapacitor (IMSC).

\subsection{Preparation of Polymer Gel Electrolyte (PGE)}

To prepare the polypropylene carbonate (PPC) polymer embedded 1-Ethyl-3-methylimidazolium-trifluoromethansulphonate [EMIM][OTf] ionic liquid-based polymer gel electrolyte (PGE), PPC was added into acetonitrile (AN) solvent in the approximate ratio of $1 \mathrm{gm}$ PPC in $5 \mathrm{~mL}$ AN. The solution was first stirred at $90{ }^{\circ} \mathrm{C}$ for $30 \mathrm{~min}$ until the PPC was completely dissolved. Then half amount of PPC, the [EMIM][OTf] ionic liquid was added in the solution to maintain the weight ratio of [EMIM][OTf]: PPC $=1: 2$ or 0.5 . This polymer solution was then stirred at $90{ }^{\circ} \mathrm{C}$ for another $30 \mathrm{~min}$ to make the solution homogeneous. To make the electrolyte viscous, this electrolyte was stirred for another $2 \mathrm{~h}$ at room temperature and finally used it for MSC device fabrication. The preparation of this PGE has been followed from one of our previous works [47].

\subsection{Fabrication of In-Plane Micro-Supercapacitor (IMSC) Devices}

The laser-induced interdigital structured graphene electrodes to prepare LIGs/ /LIGs symmetric IMSC is realized as shown schematically in Figure 8. Before the components were assembled to fabricate the MSC, the laser-induced graphene (LIG) printed electrodes were washed several times using deionized water and isopropanol solution. The interdigital electrodes were used as stability-providing components such as electrodes as well as current collectors. For electrical connection, single sided copper SEM adhesive tape was used as shown in Figure 8. Approximately, $50 \mu \mathrm{L}$ of the [EMIM][OTf]: PPC electrolyte was dropped on the active electrode surface and dried overnight in a vacuum desiccator before further electrochemical characterization is performed.

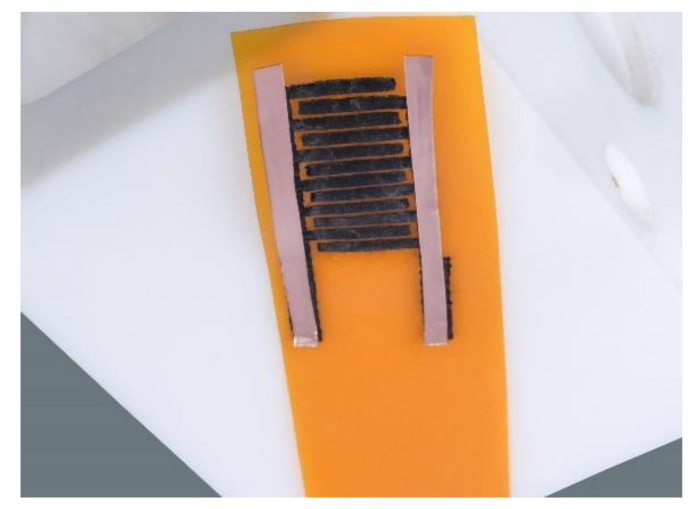

Figure 8. Fabrication of porous LIG -electrodes based in-plane micro-supercapacitor (IMSC). 


\subsection{Characterizations}

To investigate the morphology of the samples, the field-emission scanning electron microscopy (FE-SEM) images were produced using an Ultra 55 from Zeiss (Jena, Germany). The samples were glued to a standard aluminum sample carrier by means of conductive carbon adhesive pad. The SE in lens detector with an accelerating voltage of $5 \mathrm{kV}$ and a working distance of approximately $8.5 \mathrm{~mm}$ was used for this measurement. Depending on requirements, images were taken with magnifications between 115 and $50 \mathrm{k}$. The X-ray diffractograms (XRD) were taken to investigate the material conversion from polyimide (PI) to graphene-like structure and to confirm using a Bruker D8 Advance with a Göbel mirror employing $\mathrm{Cu} \mathrm{K} \mathrm{K}_{\alpha}$ radiation with $\lambda=1.54 \AA$ in the $2 \theta$ range of $15-60^{\circ}$. The scan type was "Coupled Two Theta/Theta Bragg-Brentano" at a scan speed $1 \mathrm{~s} / \mathrm{step}$ and the change in angle was $0.05^{\circ}$. Due to the small amount of the sample the silicon single crystal holder was used as sample holder. The phase analysis was performed at the DIFFRAC.EVA software from Bruker. Energy dispersive X-ray (EDX) spectroscopy measurements were also carried out to determine the elemental composition of the samples on surfaces using Aztec from Oxford Instruments (Wiesbaden, Germany). An acceleration voltage of $15 \mathrm{kV}$ was chosen for the measurement and the working distance remained the same level.

The electrochemical characterization of the LIG- based flexible micro-supercapacitors (MSCs) with a geometric electrode area of $0.72 \mathrm{~cm}^{2}$ and active mass loading of $2.0 \mathrm{mg}$ were conducted on a Gamry Reference 3000 (provided by C3 Prozess- und Analysentechnik $\mathrm{GmbH}$, Haar b. Munich, Germany) workstation using two-electrodes configuration by cyclic voltammetry (CV), electrochemical impedance spectroscopy (EIS) and galvanostatic charge-discharge (GCD) measurements. For better shielding of unwanted external effects, all the electrochemical tests were performed in the Gamry calibration shield, which itself acts as a Faraday cage. Gamry's data acquisition program Framework ${ }^{\mathrm{TM}}$ was used for parameter in-put and visualization of the running measurements. The areal capacitance $\left(\mathrm{C}_{\mathrm{A}}, \mathrm{mF} / \mathrm{cm}^{2}\right)$ and specific capacitance $\left(\mathrm{C}_{\mathrm{m}}, \mathrm{mF} / \mathrm{g}\right)$ of a supercapacitor can be calculated by CV or GCD techniques using Equations (1) and (2) or (5) and (6). The areal energy density $\left(E_{\mathrm{A}}, \mu \mathrm{Wh} / \mathrm{cm}^{2}\right)$ or Sp. Energy density $\left(\mathrm{E}_{\mathrm{m}}, \mathrm{Wh} / \mathrm{kg}\right)$ and areal power density $\left(\mathrm{P}_{\mathrm{A}}\right.$, $\left.\mathrm{mW} / \mathrm{cm}^{2}\right)$ or or Sp. Power density $\left(\mathrm{P}_{\mathrm{m}}, \mathrm{W} / \mathrm{kg}\right)$ can also be obtained by Equation (3) and (4) or (7) and (8) bellow, [25,31,41,48].

$$
\begin{gathered}
\mathrm{C}_{\mathrm{A}}=\frac{\int_{V_{a}}^{V_{c}} i(V) d V}{2 \times A \times \vartheta \times \Delta V} \\
\mathrm{C}_{\mathrm{A}}=\frac{I \times \Delta t}{A \times \Delta V} \\
\mathrm{E}_{\mathrm{A}}=\frac{C_{A} \times \Delta V^{2}}{7200} \\
\mathrm{P}_{\mathrm{A}}=\frac{E_{A} \times 3600}{\Delta t} \\
\mathrm{C}_{\mathrm{m}}=\frac{\int_{V_{a}}^{V_{c}} i(V) d V}{2 \times m \times \vartheta \times \Delta V} \\
\mathrm{C}_{\mathrm{m}}=\frac{I \times \Delta t}{m \times \Delta V} \\
\mathrm{E}_{\mathrm{m}}=\frac{C_{m} \times \Delta V^{2}}{7.2} \\
\mathrm{P}_{\mathrm{m}}=\frac{E_{m} \times 3600}{\Delta t}
\end{gathered}
$$


where, $\int_{V_{a}}^{V_{c}} i(V) d V$ is the area under the CV curve at a fixed scan rate $(\vartheta)(\mathrm{V} / \mathrm{s}), A$ is the geometric electrode area $\left(\mathrm{cm}^{2}\right), m$ is the active electrode mass $(\mathrm{g}), \Delta V=\left(V_{c}-V_{a}\right)=$ voltage window $(\mathrm{V}), \Delta t$ is the discharge time (s).

\section{Conclusions}

In summary, the fabrication of laser-induced graphene (LIG)-interdigital porous flexible electrodes using facile $\mathrm{CO}_{2}$-laser structuring of polyimide-based Kapton foils are demonstrated. Structural, morphological and compositional analysis have been performed using XRD, SEM and EDX studies. The micro-supercapacitor (MSC) devices are also fabricated using these LIG-electrodes and polypropylene carbonate (PPC) embedded 1-Ethyl3-methyl-imidazolium-trifluoromethansulphonate [EMIM][OTf] polymer gel electrolyte (PGE). The MSC shows excellent supercapacitive performance in a wide potential window up to $2.0 \mathrm{~V}$ compared to reported graphene and carbon based MSC. This device offers maximum areal capacitance of $1.75 \mathrm{mF} / \mathrm{cm}^{2}$ at $5 \mathrm{mV} / \mathrm{s}$ scan rate measured from $\mathrm{CV}$ measurements. This MSC device also delivers $0.256 \mu \mathrm{Wh} / \mathrm{cm}^{2}$ areal energy density $\left(\mathrm{E}_{\mathrm{A}}\right)$ at $0.03 \mathrm{~mA} / \mathrm{cm}^{2}$ and $0.11 \mathrm{~mW} / \mathrm{cm}^{2}$ areal power density $\left(\mathrm{P}_{\mathrm{A}}\right)$ at $0.10 \mathrm{~mA} / \mathrm{cm}^{2}$. The overall electrochemical performances of this LIG- interdigital MSCs are fabricated by $\mathrm{CO}_{2}$-laser structuring of PI-based Kapton foils are quite impressive for future practical application as flexible micro-supercapacitor. This LIG-porous electrode, fabrication scheme, the PPC: [EMIM][OTf] polymer gel electrolyte (PGE) and the device could be a suitable promising applicability in the field of flexible micro-supercapacitor for efficient peak energy storage.

Supplementary Materials: The following supporting information can be downloaded, Figure S1. SEM images of the surface changing due to the $\mathrm{KOH}$ etching process of PI-foil: (a) pristine PI foil, (b) PI foil with dried $\mathrm{KOH}$ and (c) after etching and washing process of PI-foil, Figure S2: Details of the technical drawing of the template of the applied IMSC cell geometry (unit in mm), Figure S3: EIS image at high frequency region of this LIG-MSC device. Table S1: Some values calculated from GCD curves of this LIG-MSC device.

Author Contributions: A.R., conceptualization, investigation, data analysis, writing-original manuscript preparation, review and editing; J.R., conceptualization, LIG-electrode preparation, micro-supercapacitor (MSC) cell fabrication, performed the experiments, electrolyte preparation and review of the manuscript; B.S., supervision, conceptualization, investigation, project administration, funding acquisition, visualization, validation, writing-review and editing. All authors have reviewed the manuscript and agreed to the published version of the manuscript.

Funding: Apurba Ray (personal ref. no. 91752702) gratefully acknowledges the Postdoctoral grant given in the frame of the DLR/DAAD Fellowship Program with the fellowship number 363 to conduct this research.

Institutional Review Board Statement: Not applicable.

Informed Consent Statement: Not applicable.

Data Availability Statement: The data presented in this work are available in the article and supplementary materials.

Acknowledgments: The authors acknowledge the internal funding provided by the DLR's Space Program Directory in the frame of the projects; Peak Power Platform (PPP) and Hybrid Solar powered Energy Storage (HySES).

Conflicts of Interest: The authors declare no conflict of interest.

Sample Availability: Samples of the compounds are not available from the authors.

\section{References}

1. Li, X.; Li, H.; Fan, X.; Shi, X.; Liang, J. 3D-Printed Stretchable Micro-Supercapacitor with Remarkable Areal Performance. Adv. Energy Mater. 2020, 10, 1903794. [CrossRef]

2. Mohamed, M.G.; Ahmed, M.M.M.; Du, W.T.; Kuo, S.W. Meso/microporous carbons from conjugated hyper-crosslinked polymers based on tetraphenylethene for high-performance $\mathrm{CO}_{2}$ capture and supercapacitor. Molecules 2021, 26, 738. [CrossRef] [PubMed] 
3. Kim, H.G.; Kim, Y.S.; Kwac, L.K.; Shin, H.K. Characterization of Activated Carbon Paper Electrodes Prepared by Rice HuskIsolated Cellulose Fibers for Supercapacitor Applications. Molecules 2020, 25, 3951. [CrossRef] [PubMed]

4. Lee, S.H.; Lee, J.; Jung, J.; Cho, A.R.; Jeong, J.R.; Dang Van, C.; Nah, J.; Lee, M.H. Enhanced Electrochemical Performance of Micro-Supercapacitors Via Laser-Scribed Cobalt/Reduced Graphene Oxide Hybrids. ACS Appl. Mater. Interfaces 2021, 13, 18821-18828. [CrossRef] [PubMed]

5. Roy, A.; Ray, A.; Saha, S.; Ghosh, M.; Das, T.; Satpati, B.; Nandi, M.; Das, S. NiO-CNT composite for high performance supercapacitor electrode and oxygen evolution reaction. Electrochim. Acta 2018, 283, 327-337. [CrossRef]

6. Tabassum, H.; Guo, W.; Meng, W.; Mahmood, A.; Zhao, R.; Wang, Q.; Zou, R. Metal-Organic Frameworks Derived Cobalt Phosphide Architecture Encapsulated into B/N Co-Doped Graphene Nanotubes for All pH Value Electrochemical Hydrogen Evolution. Adv. Energy Mater. 2017, 7, 1601671. [CrossRef]

7. Lethien, C.; Le Bideau, J.; Brousse, T. Challenges and prospects of 3D micro-supercapacitors for powering the internet of things Energy Environ. Sci. 2019, 12, 96-115. [CrossRef]

8. Hong, X.; He, L.; Ma, X.; Yang, W.; Chen, Y.; Zhang, L.; Yan, H.; Li, Z.; Mai, L. Microstructuring of carbon/tin quantum dots via a novel photolithography and pyrolysis-reduction process. Nano Res. 2017, 10, 3743-3753. [CrossRef]

9. $\quad$ Létiche, M.; Brousse, K.; Demortière, A.; Huang, P.; Daffos, B.; Pinaud, S.; Respaud, M.; Chaudret, B.; Roussel, P.; Buchaillot, L.; et al. Sputtered Titanium Carbide Thick Film for High Areal Energy on Chip Carbon-Based Micro-Supercapacitors. Adv. Funct. Mater. 2017, 27, 1606813. [CrossRef]

10. Huang, P.; Lethien, C.; Pinaud, S.; Brousse, K.; Laloo, R.; Turq, V.; Respaud, M.; Demortière, A.; Daffos, B.; Taberna, P.L.; et al. On-chip and freestanding elastic carbon films for micro-supercapacitors. Science 2016, 351, 691-695. [CrossRef]

11. El-Kady, M.F.; Kaner, R.B. Scalable fabrication of high-power graphene micro-supercapacitors for flexible and on-chip energy storage. Nat. Commun. 2013, 4, 1475. [CrossRef] [PubMed]

12. Wang, Y.; Sun, L.; Xiao, D.; Du, H.; Yang, Z.; Wang, X.; Tu, L.; Zhao, C.; Hu, F.; Lu, B. Silicon-based 3D all-solid-state microsupercapacitor with superior performance. ACS Appl. Mater. Interfaces 2020, 12, 43864-43875. [CrossRef] [PubMed]

13. He, W.; Wu, B.; Lu, M.; Li, Z.; Qiang, H. Fabrication and performance of self-supported flexible cellulose nanofibrils/reduced graphene oxide supercapacitor electrode materials. Molecules 2020, 25, 2793. [CrossRef] [PubMed]

14. Zhao, W.; Jiang, M.; Wang, W.; Liu, S.; Huang, W.; Zhao, Q. Flexible Transparent Supercapacitors: Materials and Devices. Adv. Funct. Mater. 2021, 31, 2009136. [CrossRef]

15. Chen, Z.; Chen, Y.; Zhao, Y.; Qiu, F.; Jiang, K.; Huang, S.; Ke, C.; Zhu, J.; Tranca, D.; Zhuang, X. B/N-Enriched Semi-Conductive Polymer Film for Micro-Supercapacitors with AC Line-Filtering Performance. Langmuir 2021, 37, 2523-2531. [CrossRef]

16. Schubert, M.; Hanft, D.; Nazarenus, T.; Exner, J.; Nieke, P.; Glosse, P.; Leupold, N.; Kita, J.; Moos, R. Powder aerosol deposition method-Novel applications in the field of sensing and energy technology. Funct. Mater. Lett. 2019, 12, 1930005. [CrossRef]

17. Asbani, B.; Robert, K.; Roussel, P.; Brousse, T.; Lethien, C. Asymmetric micro-supercapacitors based on electrodeposited Ruo2 and sputtered VN films. Energy Storage Mater. 2021, 37, 207-214. [CrossRef]

18. Saha, S.; Maji, P.; Pethsangave, D.A.; Roy, A.; Ray, A.; Some, S.; Das, S. Effect of morphological ordering on the electrochemical performance of $\mathrm{MnO}_{2}$-Graphene oxide composite. Electrochim. Acta 2019, 317, 199-210. [CrossRef]

19. Ghosh, M.; Ray, A.; Rao, G.M. Performance dependence of electrochemical capacitor on surface morphology for vertically aligned graphene nanosheets. Ionics 2020, 26, 981-990. [CrossRef]

20. Shinde, N.M.; Shinde, P.V.; Mane, R.S.; Ho Kim, K. Solution-method processed Bi-type nanoelectrode materials for supercapacitor applications: A review. Renew. Sustain. Energy Rev. 2021, 135, 110084. [CrossRef]

21. Johra, F.T.; Lee, J.W.; Jung, W.G. Facile and safe graphene preparation on solution based platform. J. Ind. Eng. Chem. 2014, 20, 2883-2887. [CrossRef]

22. Siburian, R.; Sihotang, H.; Lumban Raja, S.; Supeno, M.; Simanjuntak, C. New route to synthesize of graphene nano sheets. Orient. J. Chem. 2018, 34, 182-187. [CrossRef]

23. Li, D.; Gong, Y.; Wang, M.; Pan, C. Preparation of sandwich-like $\mathrm{NiCo}_{2} \mathrm{O}_{4} / \mathrm{rGO} / \mathrm{NiO}$ heterostructure on nickel foam for high-performance supercapacitor electrodes. Nano Micro Lett. 2017, 9, 16. [CrossRef]

24. Hao, Y.; Wang, C. Free-standing Reduced Graphene Oxide/Carbon Nanotube Paper for Flexible Sodium-ion Battery Applications. Molecules 2020, 25, 1014.

25. Chen, G.; Zhang, X.; Ma, Y.; Song, H.; Pi, C.; Zheng, Y.; Gao, B.; Fu, J.; Chu, P.K. In-situ synthesis of heterostructured carbon-coated $\mathrm{Co} / \mathrm{MnO}$ nanowire arrays for high-performance anodes in asymmetric supercapacitors. Molecules 2020, 25, 3218. [CrossRef]

26. Tian, W.; Li, Y.; Zhou, J.; Wang, T.; Zhang, R.; Cao, J.; Luo, M.; Li, N.; Zhang, N.; Gong, H.; et al. Implantable and biodegradable micro-supercapacitor based on a superassembled three-dimensional network Zn@ppy hybrid electrode. ACS Appl. Mater. Interfaces 2021, 13, 8285-8293. [CrossRef]

27. Munuera, J.M.; Paredes, J.I.; Enterría, M.; Villar-Rodil, S.; Kelly, A.G.; Nalawade, Y.; Coleman, J.N.; Rojo, T.; Ortiz-Vitoriano, N.; Martínez-Alonso, A.; et al. High Performance Na-O $\mathrm{O}_{2}$ Batteries and Printed Microsupercapacitors Based on Water-Processable, Biomolecule-Assisted Anodic Graphene. ACS Appl. Mater. Interfaces 2020, 12, 494-506. [CrossRef]

28. Bhagwan, J.; Rani, S.; Sivasankaran, V.; Yadav, K.L.; Sharma, Y. Improved energy storage, magnetic and electrical properties of aligned, mesoporous and high aspect ratio nanofibers of spinel-NiMn ${ }_{2} \mathrm{O}_{4}$. Appl. Surf. Sci. 2017, 426, 913-923. [CrossRef]

29. Pitkänen, O.; Eraslan, T.; Sebok, D.; Szenti, I.; Kukovecz, Á.; Vajtai, R.; Kordas, K. Flexible planar supercapacitors by straightforward filtration and laser processing steps. Nanotechnology 2020, 31, 495403. [CrossRef] 
30. Karbhal, I.; Basu, A.; Patrike, A.; Shelke, M.V. Laser patterning of boron carbon nitride electrodes for flexible micro-supercapacitor with remarkable electrochemical stability/capacity. Carbon 2021, 171, 750-757. [CrossRef]

31. Yadav, P.; Basu, A.; Suryawanshi, A.; Game, O.; Ogale, S. Highly Stable Laser-Scribed Flexible Planar Microsupercapacitor Using Mushroom Derived Carbon Electrodes. Adv. Mater. Interfaces 2016, 3, 1600057. [CrossRef]

32. Xu, C.; Jiang, L.; Li, X.; Li, C.; Shao, C.; Zuo, P.; Liang, M.; Qu, L.; Cui, T. Miniaturized high-performance metallic 1T-Phase MoS2 micro-supercapacitors fabricated by temporally shaped femtosecond pulses. Nano Energy 2020, 67, 104260. [CrossRef]

33. Tahir, M.; He, L.; Yang, W.; Hong, X.; Haider, W.A.; Tang, H.; Zhu, Z.; Owusu, K.A.; Mai, L. Boosting the electrochemical performance and reliability of conducting polymer microelectrode via intermediate graphene for on-chip asymmetric microsupercapacitor. J. Energy Chem. 2020, 49, 224-232. [CrossRef]

34. Yoo, J.J.; Balakrishnan, K.; Huang, J.; Meunier, V.; Sumpter, B.G.; Srivastava, A.; Conway, M.; Mohana Reddy, A.L.; Yu, J.; Vajtai, R.; et al. Ultrathin planar graphene supercapacitors. Nano Lett. 2011, 11, 1423-1427. [CrossRef]

35. Saha, S.; Sadhukhan, P.; Roy Chowdhury, S.; Das, S. Rotary-Jet spin assisted fabrication of $\mathrm{MnO}_{2}$ microfiber for supercapacitor electrode application. Mater. Lett. 2020, 277, 128342. [CrossRef]

36. Ray, A.; Roy, A.; Ghosh, M.; Ramos-ramón, J.A.; Saha, S. Applied Surface Science Study on charge storage mechanism in working electrodes fabricated by sol- gel derived spinel $\mathrm{NiMn}_{2} \mathrm{O}_{4}$ nanoparticles for supercapacitor application. Appl. Surf. Sci. 2019, 463, 513-525. [CrossRef]

37. Bhattacharya, G.; Kandasamy, G.; Soin, N.; Upadhyay, R.K.; Deshmukh, S.; Maity, D.; McLaughlin, J.; Roy, S.S. Novel $\pi$-conjugated iron oxide/reduced graphene oxide nanocomposites for high performance electrochemical supercapacitors. RSC Adv. 2017, 7 , 327-335. [CrossRef]

38. Kim, S.K.; Koo, H.J.; Lee, A.; Braun, P.V. Selective wetting-induced micro-electrode patterning for flexible micro-supercapacitors Adv. Mater. 2014, 26, 5108-5112. [CrossRef] [PubMed]

39. Meng, J.; Wu, G.; Wu, X.; Cheng, H.; Xu, Z.; Chen, S. Microfluidic-Architected Nanoarrays/Porous Core-Shell Fibers toward Robust Micro-Energy-Storage. Adv. Sci. 2020, 7, 1901931. [CrossRef]

40. Ray, A.; Saruhan, B. Application of ionic liquids for batteries and supercapacitors. Materials 2021, 14, 2942. [CrossRef]

41. Ray, A.; Roy, A.; Saha, S.; Ghosh, M.; Chowdhury, S.R.; Maiyalagan, T.; Bhattacharya, S.K.; Das, S. Electrochemical Energy Storage Properties of Ni-Mn-Oxide Electrodes for Advance Asymmetric Supercapacitor Application. Langmuir 2019, 35, 8257-8267. [CrossRef]

42. Dai, S.; Guo, H.; Wang, M.; Liu, J.; Wang, G.; Hu, C.; Xi, Y. A Flexible micro-supercapacitor based on a pen ink-carbon fiber thread J. Mater. Chem. A 2014, 2, 19665-19669. [CrossRef]

43. Ferris, A.; Garbarino, S.; Guay, D.; Pech, D. 3D RuO 2 microsupercapacitors with remarkable areal energy. Adv. Mater. 2015, 27, 6625-6629. [CrossRef] [PubMed]

44. Zhang, W.; Li, R.; Zheng, H.; Bao, J.; Tang, Y.; Zhou, K. Laser-Assisted Printing of Electrodes Using Metal-Organic Frameworks for Micro-Supercapacitors. Adv. Funct. Mater. 2021, 31, 2009057. [CrossRef]

45. Lin, J.; Zhang, C.; Yan, Z.; Zhu, Y.; Peng, Z.; Hauge, R.H.; Natelson, D.; Tour, J.M. 3-Dimensional Graphene Carbon Nanotube Carpet-Based Microsupercapacitors With High Electrochemical Performance. Nano Lett. 2013, 13, 72-78. [CrossRef] [PubMed]

46. Zeng, Y.X.; Han, Y.; Zhao, Y.T.; Zeng, Y.; Yu, M.H.; Liu, Y.J.; Tang, H.L.; Tong, Y.X.; Lu, X.H. Advanced Ti-Doped Fe $2 \mathrm{O}_{3} @ P E D O T$ Core/Shell Anode for High-Energy Asymmetric Supercapacitors. Adv. Energy Mater. 2015, 5, 1402176. [CrossRef]

47. Ray, A.; Korkut, D.; Saruhan, B. Efficient flexible all-solid supercapacitors with direct sputter-grown needle-like mn/mnox @graphite-foil electrodes and ppc-embedded ionic electrolytes. Nanomaterials 2020, 10, 1768. [CrossRef]

48. Wang, X.; Wu, D.; Song, X.; Du, W.; Zhao, X.; Zhang, D. Review on carbon/polyaniline hybrids: Design and synthesis for supercapacitor. Molecules 2019, 24, 2263. [CrossRef] 